\title{
Developing critical thinking, creativity and innovation skills of undergraduate students
}

\section{Barry Shoop}

Barry L. Shoop, "Developing critical thinking, creativity and innovation skills of undergraduate students," Proc. SPIE 9289, 12th Education and Training in Optics and Photonics Conference, 928904 (17 July 2014); doi: $10.1117 / 12.2068495$

SPIE Event: 12th Education and Training in Optics and Photonics Conference, 2013, Porto, Portugal 


\title{
Developing Critical Thinking, Creativity and Innovation Skills of Undergraduate Students
}

\author{
Barry L. Shoop \\ Department of Electrical Engineering and Computer Science, U.S. Military Academy, \\ West Point, NY 10996
}

\begin{abstract}
A desirable goal of engineering education is to teach students how to be creative and innovative. However, the speed of technological innovation and the continual expansion of disciplinary knowledge leave little time in the curriculum for students to formally study innovation. At West Point we have developed a novel upper-division undergraduate course that develops the critical thinking, creativity and innovation of undergraduate science and engineering students. This course is structured as a deliberate interactive engagement between students and faculty that employs the Socratic method to develop an understanding of disruptive and innovative technologies and a historical context of how social, cultural, and religious factors impact the acceptance or rejection of technological innovation. The course begins by developing the background understanding of what disruptive technology is and a historical context about successes and failures of social, cultural, and religious acceptance of technological innovation. To develop this framework, students read The Innovator's Dilemma by Clayton M. Christensen, The Structure of Scientific Revolutions by Thomas S. Kuhn, The Discoverers by Daniel J. Boorstin, and The Two Cultures by C.P. Snow. For each class meeting, students survey current scientific and technical literature and come prepared to discuss current events related to technological innovation. Each student researches potential disruptive technologies and prepares a compelling argument of why the specific technologies are disruptive so they can defend their choice and rationale. During course meetings students discuss the readings and specific technologies found during their independent research. As part of this research, each student has the opportunity to interview forward thinking technology leaders in their respective fields of interest. In this paper we will describe the course and highlight the results from teaching this course over the past five years.
\end{abstract}

Keywords: Critical thinking skills; creativity; innovation; disruptive technology

\section{BACKGROUND AND MOTIVATION}

For decades there has been a seemingly continuous call for engineering education reform to improve critical thinking, creativity and innovation of engineering students. In 1968, Daniel V. De Simone from the U.S. Department of Commerce claimed that engineering education stressed the acquisition of knowledge and skills of analysis and effectively stifled creativity and innovation [1]. Others have noted that the rapid increase in scientific knowledge and emerging technologies have placed increased pressures on engineering curricula to expand technical content, often at the expense of creativity, critical thinking and innovation $[2,3]$.

While the literature is replete with calls for engineering education reform, research on successful change is far more sparse. Those reported can be broadly categorized as the addition of new courses, modifications to curricula and courses, and pedagogical changes. Disruptive Innovations is a relatively new course that employs pedagogy not traditionally found in engineering courses. In 2010 we published the framework of this course as well as an assessment based on a course-end survey, several external indicators, a post-graduation survey and faculty assessment [4]. This current paper reviews the course structure and content and provides additional details on the course and insights from teaching the course over the past five years.

\section{A MACRO-LEVEL VIEW OF THE COURSE}

XE492 - Disruptive Innovations is a 3.0 credit, upper-division undergraduate elective course that initially began with electrical engineering and computer science honors majors and has expanded to include information technology, life

\footnotetext{
${ }^{\dagger}$ Barry.Shoop@usma.edu (O) 845.938.2200
}

12th Education and Training in Optics and Photonics Conference, edited by

Manuel F. P. C. Martins Costa, Mourad Zghal, Proc. of SPIE Vol. 9289, 928904

(c) 2014 SPIE, OSA, IEEE, ICO · doi: 10.1117/12.2068495

Proc. of SPIE Vol. 9289 928904-1 
sciences and social science majors. The course is structured as a deliberate interactive engagement between students and faculty that employs the Socratic method [5] as the pedagogical framework. Developed from Plato's Socratic dialogues, the Socratic method of teaching is a student-centered approach that develops critical thinking skills by engaging in analytic discussion.

The enduring theme of the course is to develop an understanding of disruptive and innovative technologies and a historical context of how social, cultural, and religious factors impact the acceptance or rejection of technological innovation. To develop this framework, the course is grounded in four classic texts: The Innovator's Dilemma [6] by Clayton M. Christensen, The Structure of Scientific Revolutions [7] by Thomas S. Kuhn, The Discoverers [8] by Daniel J. Boorstin, and The Two Cultures [9] by C.P. Snow. Each student independently researches potentially disruptive technologies and prepares a compelling argument of why they believe the specific technologies are disruptive so they can defend their choice and rationale. During course meetings students discuss the course readings and specific technologies found during their independent research. As part of the course, each student is also given the opportunity to interview forward thinking technology leaders in their respective fields of interest. Over the past five years, students have met with the Clayton M. Christensen, the Kim B. Clark Professor of Business Administration at the Harvard Business School, the Vice President for Innovation at IBM, the Director of the Defense Advanced Research Projects Agency (DARPA), the Chief Technology Officer of MIT Lincoln Laboratory, the Director of Disney's Imagineering, and the Vice-President of Research of iRobot, to name a few.

\subsection{Socratic Dialog}

Unlike most courses in a traditional science or engineering curriculum, this course is structured as a dialogue between students and faculty. Much like the construct of a social science course, each class meeting engages the students in a dialog about the course readings and the specific technologies that each student is researching. This construct, based on the Socratic method, is a dialectic method of inquiry that uses cross-examination of an individual's claims in order to reveal contradictions or internal inconsistencies. Many argue that Socratic questioning is at the heart of critical thinking. Socratic questioning challenges accuracy and completeness of thinking and deepens individual insights and understanding. Additionally, this approach serves to strengthen the student's skills to formulate a logical argument and the ability to effectively engage in a rational, oral debate. Throughout the course, the students are expected to use this approach as they engage in dialogs with other faculty and the technology leaders. Questions like: "How do you define disruptive technology?" and "Why do you believe that a specific technology is disruptive?" set the stage for a common vernacular from which to then continue the dialog.

The Socratic method engages the students in an intellectual dialogue that improves their understanding of the subject material, improves their critical thinking and independent thought skills, and develops their ability to engage in technical debate.

\subsection{Disruptive Technology}

Clayton M. Christensen first coined the term disruptive technology in his 1995 article "Disruptive Technologies: Catching the Wave" [10]. Later in his book, The Innovator's Dilemma, Christensen asks the question: Why do wellmanaged companies fail? He concludes that they often fail because the very management practices that have allowed them to become industry leaders also make it extremely difficult for them to recognize and develop the disruptive technologies that ultimately capture their markets.

He concludes that well-managed companies are excellent at developing sustaining technologies, those technologies that improve the performance of their products in ways that satisfy their customers. Disruptive technologies, however, are distinctly different from sustaining technologies. They are typically cheaper, smaller, simpler and frequently more convenient to use. Disruptive technologies fundamentally change the value proposition in a market according to a distinct pathology.

Christensen suggests that value networks are responsible for disruptive effects. A value network is a hierarchy of component producers and consumers, each operating at price points determined by economic forces within the network. The network as a whole produces a category of finished products, for example, disk drives, earthmoving equipment, or financial software. Disruption occurs when a value network concerned with cheaper products advances, through its own sustaining improvements, to a point where it becomes capable of adequately meeting demand in an entirely different network where price points are significantly higher. When this occurs quickly, which it often does, the disrupted network has insufficient time to adjust, and it usually perishes. 
The Linux operating system (OS) is an example of a disruptive technology. It employed a new development methodology - Open Source - that was widely viewed as inferior to proprietary forms of software engineering for complex systems. When originally introduced, its performance was also considered inferior to other server operating systems like Unix and Windows NT. But the Linux OS was inexpensive compared to other server operating systems. After years of improvements to its technology, rooted in refinements and the ultimate success of Open Source methods, Linux is now installed in $81.00 \%$ of the worlds 500 fastest supercomputers [11].

While The Innovator's Dilemma develops the broad framework for thinking about disruptive technology and understanding the business aspects necessary to recognize and successfully take advantage of them, students gain a deeper understanding of the lessons of the book by applying the concepts to specific applications.

\subsection{The Structure of Scientific Revolutions}

In The Structure of Scientific Revolutions, Thomas Kuhn argues that science does not progress through a linear accumulation of new knowledge, but instead undergoes periodic revolutions, or paradigm shifts in which the nature of scientific inquiry within a particular field is abruptly transformed. He suggests that science can be categorized in three distinct stages. Pre-paradigm or prescience phase, which lacks a central paradigm, comes first. In this phase, there is generally no consensus on a single unifying theory and there are multiple incompatible or incomplete theories which scientists pursue. As the scientific community begins to converge and develop consensus on a theory a paradigm emerges. This is followed by paradigmatic or normal science. During this stage, a paradigm has been accepted by the scientific community and subsequent research consists of applying shared methods to refine and expand the central paradigm. Normal science is characterized by Kuhn as "puzzle-solving." Over time, advances in normal science may reveal anomalies, facts that are difficult to explain within the context of the existing paradigm. While these anomalies are generally resolved, in some cases they may accumulate to the point where weaknesses in the paradigm are revealed. Kuhn refers to this as a crisis. At this point, science enters the third phase, that of revolutionary science, in which the underlying assumptions are reexamined and a new paradigm that addresses the anomalies is established. After the new paradigm is established, scientists return to normal science, solving puzzles within the new paradigm.

There are a number of reasons for including this text as one of the foundational components of this course. First, the text allows the students to gain an understanding of the scientific enterprise and process of scientific discovery not present in traditional textbooks. It introduces the concept that scientific knowledge is dependent on the culture and historical circumstances of groups of scientists rather than on their adherence to a specific, definable method. In fact, Kuhn portrays textbooks as a key reason that most people, including scientists themselves, have an artificially simplified and orderly view of scientific progress. Our scientific culture educates next-generation practitioners using these highly refined end products of previous research, wherein the messy human details of development have been scrubbed away. Kuhn, on the other hand, depicts science as a human process - mistake-prone, competitive, argumentative, with personalities and propensities of the researchers themselves playing a significant role in the rate, if not the end results, of progress. His ultimate claim is that we all benefit by recording and studying these details in order to gain a widespread meta-understanding, so that the future road of science might be smoothed and straightened. The Structure of Scientific Revolutions probably represents some the best thinking on how transformation occurs, who drives it, why it is resisted, and what it really asks of people. It is a challenging book for undergraduate students that requires careful and critical reading and thinking. Finally, it is considered one of the hundred most influential books since the Second World War by The Times Literary Supplement.

\subsection{Social, Cultural and Religious Roles in Technology Acceptance and Rejection}

The Discoverers is a non-fiction historical work by Daniel Boorstin published in 1983. The book, subtitled A History of Man's Search to Know His World and Himself, is the history of human discovery. He traces numerous scientific and technical discoveries and identifies obstacles set up by opposing myths, traditions, religious dogma and the dictates of earlier authority. More broadly he includes cultural, societal, and religious influences in scientific discovery and advances. He does a masterful job of documenting discoveries by focusing on an individual and incremental approach to history. The purpose for including this text as a foundational course component is to help the student understand that acceptance or rejection of technological innovations depends on factors beyond the control of the technologist including social, political, cultural and religious factors.

One striking example of technological innovation and its lack of wide-spread acceptance dealt with shipbuilding and exploration. During the period when Prince Henry the Navigator was just beginning to explore the West coast of Africa, the Chinese had already built massive flotillas consisting of as many as 317 ships and had advanced the state-of-the-art 
of shipbuilding well beyond that elsewhere in the world. Bulkheads which divided the ship's hold into compartments to prevent flooding and fires and were first integrated by the Chinese are believed to have been inspired by the septa, the transverse membranes in bamboo. But the Chinese were not traders, conquerors or crusaders. While the purpose of most other navies was to explore, expand and conquer, the purpose of the Chinese navy was instead to display the splendor and power of the new Ming dynasty. After only a brief and limited seafaring excursion with the most advanced shipbuilding technology of its day, the Chinese reverted to an inward focus. While the Chinese developed the technological innovations necessary to position them as a seafaring nation, capable of exploration and expansion, their culture and beliefs prevented adoption and further development.

\subsection{The Two Cultures}

Charles Percy Snow - C. P. Snow - was an English physicist and novelist. In 1956 he published an article entitled "The Two Cultures" [12] and later in 1959 delivered the Cambridge University Rede Lecture entitled "The Two Cultures and the Scientific Revolution" on which the book The Two Cultures is based. Snow's thesis was that "the intellectual life of the whole of western society is increasingly being split into two polar groups," [13]. "Literary intellectuals at one pole at the other scientists. Between the two a gulf of mutual incomprehension - sometimes (particularly among the young) hostility and dislike, but most of all lack of understanding" [14]. Snow effectively argues that practitioners from the sciences and the humanities should build bridges to further the progress of human knowledge and to benefit society. This book reinforces a common theme in the course to think more broadly about a topic, and particularly about technology innovation acceptance.

\subsection{Engagement with Forward Thinking Technology Leaders}

An integral component of the course is to provide a venue to extend the dialogue outside of the classroom with forward thinking technology leaders. The purpose of this component of the course is to provide the students an opportunity to engage in a dialogue with senior technology leaders about disruptive technology, technology innovation and business processes associated with technology development. This component is structured in a way to reinforce the foundational course content while simultaneously providing an opportunity for students to probe more deeply into select technologies. Some of the "thought leaders" are leaders of commercial and government organizations that develop new technologies. From these leaders the students can probe business management and organizational structure that encourages innovation. Others are renowned researchers and professors who have deep technical insights in specific technologies. This second group is identified each semester according to student topical interest and provides the opportunity to gain additional insights about the specific technology that they are investigating.

This last component takes several forms but the underlying venue remains the same - a one-on-one conversation between the students and the forward thinking technology leaders. Each semester, several trips are organized to allow the students to meet with select leaders at their respective organizations. In addition to supplement these trips, a wide-range of prominent guest speakers are routinely available who can be enlisted to discuss similar business or technical subject areas.

\subsection{Written Communication Skills}

The culminating component of the course is a written paper suitable for submission to a conference or journal. The format is a five-to-seven page, double column paper modeled after a traditional scientific or engineering journal article. Throughout the course, students submit one-to-three page papers on the primary course readings. These papers are critiqued by the faculty and are also peer-reviewed and critiqued by at least one other student. The peer-review process is generally done by a student from a different disciplinary field and provides both students additional insights into the common reading. These short papers then form the basis of the final paper which also incorporates the specific technology that the student defines and defends as being potentially disruptive.

\section{A MICRO-LEVEL VIEW OF THE COURSE}

Prior to academic year 2013, the course was taught as an independent study course. During academic year 2012, the West Point Curriculum Committee formally approved XE492 Disruptive Innovations as a new course offered through the Department of Electrical Engineering and Computer Science. At West Point, course designations of XE $\times \times \times$ refer to interdisciplinary engineering courses while $\mathrm{XH} \times \times \times$ refer to interdisciplinary humanities courses. This designation 
facilitates ease of interdisciplinary enrollment. XE492 was approved with the learning outcomes and objectives, learning model and assessment plan described below.

\subsection{Course Learning Outcomes and Objectives}

a) Understand the nature of disruptive and innovative technologies

- Be able to identify and assess disruptive technologies from the past. Identify successes and failures of social, cultural, and religious acceptance of technological innovation.

b) Identify potential future disruptive and innovative technologies

- Research potential disruptive and innovative technologies within their area of expertise and develop compelling arguments of why the specific technologies are disruptive.

c) Develop critical thinking, creativity, and innovation skills

- Engage students in an intellectual dialogue that improves their understanding of the subject material, improves their critical thinking and independent thought skills, and develops their ability to engage in technical debate.

\subsection{Learning Model}

This course helps students develop the rationale framework to analyze a changing technological, social, political and economic world and help anticipate changes that might result. The learning process in this course begins with the analysis of technological disruptions and innovations and the structure of scientific revolutions culminating with students researching and identifying potentially disruptive commercial technologies.

a) Structure. The course provides a rational approach to identifying and analyzing disruptive and innovative technologies. By exploring historical examples, cadets understand how disruptive technologies not only appear but how the adoption mechanism can have profound societal and economic impacts. The course is structured as a deliberate interactive engagement between students and faculty that employs the Socratic method to develop an understanding of disruptive and innovative technologies and a historical context of how social, cultural, and religious factors impact the acceptance or rejection of technological innovation.

b) Process. By means of class discussion, in-depth readings, summary papers, technology innovator interviews, and a final research project; students learn how to identify potential disruptive technologies and analyze probable impacts. By the end of the course, students identify a potentially disruptive technology, defend their rationale, and explore possible impacts.

c) Content. The course is based upon detailed discussion of multiple texts: The Innovator's Dilemma by Clayton M. Christensen, The Structure of Scientific Revolutions by Thomas S. Kuhn, The Discoverers by Daniel J. Boorstin, and The Two Cultures by C.P. Snow. Daily technical current event content is taken from discipline appropriate technical journals and articles.

\subsection{Assessment Plan}

\begin{tabular}{|l|l|l|}
\hline LEARNING OBJECTIVE & EXPECTED OUTCOME & INDICATOR \\
\hline $\begin{array}{l}\text { Understand the nature of disruptive } \\
\text { and innovative technologies }\end{array}$ & $\begin{array}{l}\text { Be able to identify and assess disruptive } \\
\text { technologies from the past. Identify successes } \\
\text { and failures of social, cultural, and religious } \\
\text { acceptance of technological innovation. }\end{array}$ & $\begin{array}{l}\text { 3-page summary on disruptive technology } \\
\text { 3-page summary on scientific revolutions } \\
\text { 1-page paper on technological acceptance or rejection } \\
\text { based on social, political, and religious implications } \\
\text { 1-page summary of the two cultures } \\
\text { Course end survey }\end{array}$ \\
\hline $\begin{array}{l}\text { Identify potential future disruptive } \\
\text { and innovative technologies }\end{array}$ & $\begin{array}{l}\text { Research potential disruptive or innovative } \\
\text { technologies within their area of expertise and } \\
\text { develop compelling arguments of why the } \\
\text { specific technologies are disruptive. }\end{array}$ & $\begin{array}{l}\text { Discussion of current events in technology } \\
\text { Innovator out briefs } \\
\text { Final 5-7 page, double column paper }\end{array}$ \\
\hline $\begin{array}{l}\text { Apply course knowledge by } \\
\text { engaging in a technical dialog with } \\
\text { forward-thinking technology } \\
\text { leaders }\end{array}$ & $\begin{array}{l}\text { Effective technical dialog between the student } \\
\text { and the forward thinking technology leader }\end{array}$ & $\begin{array}{l}\text { Faculty assessment of a deeper understanding of } \\
\text { foundational concepts and ability to engage in a Socratic } \\
\text { dialog }\end{array}$ \\
\hline
\end{tabular}




\subsection{Syllabus}

\begin{tabular}{|c|c|c|c|}
\hline Lesson & Topic & Assignment & Event \\
\hline 1 & Course Overview & None & \\
\hline \multicolumn{4}{|c|}{ Foundations: Disruptive Technologies - The Innovator's Dilemma, Clayton M. Christensen } \\
\hline 2 & Why Great Companies Can Fail & Part One - to pg. 94 & \\
\hline 3 & $\begin{array}{l}\text { Managing Disruptive Technological } \\
\text { Change }\end{array}$ & Part Two - to pg. 142 & \\
\hline 4 & $\begin{array}{l}\text { Managing Disruptive Technological } \\
\text { Change }\end{array}$ & Part Two - to pg. 182 & \\
\hline 5 & $\begin{array}{l}\text { Managing Disruptive Technological } \\
\text { Change }\end{array}$ & Part Two - to pg. 224 & \\
\hline 6 & The Dilemmas of Innovation: A Summary & Part Two - to pg. 230 & \\
\hline 7 & Reflection & \multicolumn{2}{|r|}{ 3-page summary on disruptive technology } \\
\hline 8 & Independent Study & \multicolumn{2}{|c|}{ Investigate Individual Disruptive Technologies } \\
\hline \multicolumn{4}{|c|}{ Structure of Scientific Revolutions - Thomas S. Kuhn } \\
\hline 9 & Normal Science and Paradigms & Through pg. 42 & \\
\hline 10 & Anomalies and Crises & Through pg. 76 & \\
\hline 11 & Scientific Revolutions & Through pg. 91 & \\
\hline 12 & Independent Study & \multicolumn{2}{|c|}{ Investigate Individual Disruptive Technologies } \\
\hline 13 & Invisibility of Revolutions & Through pg. 135 & $\begin{array}{l}\text { Engagement with forward-thinking } \\
\text { technology leaders }\end{array}$ \\
\hline 14 & Resolutions and Progress & Through pg. 173 & \\
\hline 15 & Reflection & \multicolumn{2}{|r|}{ 3-page summary on scientific revolutions } \\
\hline 16 & Independent Study & \multicolumn{2}{|c|}{ Investigate Individual Disruptive Technologies } \\
\hline \multicolumn{4}{|c|}{ Social, Political, and Religious Implications - The Discoverers, Daniel J. Boorstin } \\
\hline 17 & Time & Book I - to pg. 46 & \\
\hline 18 & Time & Book I - to pg. 78 & \\
\hline 19 & The Earth and the Seas & Book II - to pg. 113 & \\
\hline 20 & The Earth and the Seas & Book II - to pg. 143 & \\
\hline 21 & The Earth and the Seas & Book II - to pg. 201 & \\
\hline 22 & The Earth and the Seas & Book II - to pg. 244 & $\begin{array}{l}\text { 1-page paper on social, political, and } \\
\text { religious implications }\end{array}$ \\
\hline 23 & The Earth and the Seas & Book II - to pg. 289 & \\
\hline 24 & Nature & Book III - to pg. 332 & \\
\hline 25 & Nature & Book III - to pg. 376 & \\
\hline 26 & Nature & Book III - to pg. 408 & \\
\hline 27 & Nature & Book III - to pg. 476 & \\
\hline 28 & Society & Book IV - to pg. 547 & \\
\hline 29 & Society & Book IV - to pg. 675 & \\
\hline 30 & Reflection & & $\begin{array}{l}\text { 3-page summary of social, political, } \\
\text { and religious implications }\end{array}$ \\
\hline \multicolumn{4}{|c|}{ Cultural Implications - The Two Cultures, C. P. Snow } \\
\hline 31 & & Introduction & \\
\hline 32 & The Rede Lecture & Through pg. 52 & \\
\hline 33 & The two cultures and the implications & Through pg. 100 & 1-page summary of the Two Cultures \\
\hline 34 & Reflection & & \\
\hline \multicolumn{4}{|c|}{ Disruptive and Innovative Commercial Technologies } \\
\hline 35 & $\begin{array}{l}\text { Piecing it together: disruptive commercial } \\
\text { technologies }\end{array}$ & & $\begin{array}{l}\text { Engagement with forward-thinking } \\
\text { technology leaders }\end{array}$ \\
\hline 36 & $\begin{array}{l}\text { Piecing it together: disruptive commercial } \\
\text { technologies }\end{array}$ & & \\
\hline 37 & $\begin{array}{l}\text { Piecing it together: disruptive commercial } \\
\text { technologies }\end{array}$ & & \\
\hline 38 & Overview of final disruptive technologies & & Discussions and final refinement \\
\hline 39 & Final paper preparation & & \\
\hline 40 & Course Assessment & & Final 5-7 page, double column paper \\
\hline
\end{tabular}




\section{INSIGHTS}

There are a number of insights from the development and execution of this course that merit discussion. First, the Socratic dialog approach used in this course is, at first, foreign to the students and therefore they are initially not comfortable engaging in debate, especially with the faculty. However, as the course progresses and the students become more comfortable with the format, they begin to see the merits of the approach as they develop a deeper understanding of the subjects.

An additional advantage to the course construct comes from the diversity of the student's disciplinary backgrounds. This provides diversity of perspective during the class discussions but also presents a challenge for a single faculty member, requiring substantial preparation to engage in the discussions of a wide variety of specific disruptive technologies. This course also provides a tremendous opportunity for students to integrate knowledge of economics, politics, human psychology, historical study methods, and others. This is a strength of the core curriculum at West Point and is an important reason for the success of the course.

While the course as it is currently structured is successful in achieving its goals, the question of scalability must be addressed. Fundamentally, this course is resource intensive, requiring substantial faculty time to prepare and conduct the course. In order to support the Socratic dialog format, the course enrollment must necessarily be small - enrollment beyond about 8-10 students would reduce the impact of the dialog. Additionally, the breadth of the course topical discussions resulting from the diversity of student disciplines requires a senior, more experienced faculty member who is well-grounded in foundations of physics, chemistry, biology, and their applications to a variety of engineering and science applications.

Finally, the course is substantially shaped by the selection of the course readings. One possible change under consideration is to supplement the course readings with excerpts from other, more contemporary books or books that address specific desired topical coverage such as The Next 100 Years [15] by George Friedman, Diffusion of Innovations [16] by Everett Rogers, The World is Flat [17] or Hot, Flat and Crowded [18] by Thomas Friedman, or The Black Swan [19] by Nassim Taleb, to name a few. These additional texts could be used to further shape the course and the dialogs and provide an opportunity for students to apply their critical thinking skills to more contemporary works.

\section{REFERENCES}

[1] De Simone, D. V., "Education for innovation," IEEE Spectrum, 5(1), 83-89 (1968).

[2] Splitt, F., "Systemic engineering education reform: A grand challenge," The Bent of Tau Beta Pi, 29-34 (2003).

[3] Moore, D. J. and Voltmer, D. R., "Curriculum for an engineering renaissance," IEEE Transactions on Education, 46(4), 452-455 (2003).

[4] Shoop, B. L., and E. K. Ressler, "Developing the critical thinking, creativity and innovation skills of undergraduate engineering students," International Journal of Engineering Education, (27)5, 1072-1080 (2011).

[5] Saran, R. and Neisser, B., "Enquiring minds, Socratic dialogue in education," Trentham Books Ltd., Sterling, VA (2004).

[6] Christensen, C. M., The Innovator's Dilemma, Harvard Business School Press, Boston, Massachusetts (1997).

[7] Kuhn, T. S., The Structure of Scientific Revolutions, University of Chicago Press, Chicago, Illinois (1996).

[8] Boorstin, D. J., The Discoverers - A History of Man's Search to Know His World and Himself, Random House, Inc., New York (1985).

[9] Snow, C. P., The Two Cultures, Cambridge University Press, Cambridge, UK (1998).

[10] Bower, J. L., and Christensen, C. M., "Disruptive technologies: Catching the wave," Harvard Business Review, 73(1), 43-53 (1995).

[11] Operating System share for 06/2010 | TOP500 Supercomputer Sites, http://www.top500.org/stats/list/35/os, (4 October 2010).

[12] Snow, C. P., The Two Cultures, New Statesman and Nation, 52, 413-414 (1956).

[13] Snow, C. P., The Two Cultures, Cambridge University Press, Cambridge, UK, 3 (1998).

[14] Snow, C. P., The Two Cultures, Cambridge University Press, Cambridge, UK, 4 (1998).

[15] Friedman, G., The Next 100 Years, A Forecast for the $21^{\text {st }}$ Century, Doubleday, New York (2009).

[16] Rogers, E. M., Diffusion of Innovations, Free Press, New York (1995).

[17] Friedman, T. L., The World is Flat: A Brief History of the Twenty-First Century, Farrar, Straus, and Giroux, New York (2005).

[18]Friedman, T. L., Hot, Flat and Crowded, Why We Need a Green Revolution - and How it Can Renew America, Farrar, Straus, and Giroux, New York (2008).

[19] Taleb, N. N., The Black Swan: The Impact of the Highly Improbable, Random House, New York (2007). 